\title{
Heterosexual Contact
}

National Cancer Institute

\section{Source}

National Cancer Institute. Heterosexual Contact. NCI Thesaurus. Code C154862.

Sexual contact with someone of the opposite sex. 